\title{
Analisis Tarif Tol Berdasarkan Ability to Pay dan Willingness to Pay Rencana Jalan Tol Jakarta - Cikampek II Selatan
}

\author{
Ikhwannudin Ekocahyanto $^{1)}$, Iwan Supriyadi ${ }^{2)}$ \\ ${ }^{1,2)}$ Program Studi Teknik Perancangan Jalan dan Jembatan, Politeknik Negeri Jakarta \\ Jl. Prof. Dr.G. A.Siwabessy, Kampus UI Depok, 16424 \\ Email: ikhwannudin.ndn@gmail.com, iwan.supriyadi@pnj.ac.id
}

\begin{abstract}
Abstrak
Proyek Jalan Tol Jakarta-Cikampek II Selatan merupakan salah satu Proyek Strategis Nasional yang diharapkan dapat memperlancar distribusi barang dan jasa menurunkan biaya logistik, mendukung potensi ekonomi kawasan industri. Menurut PP nomor 15 tahun 2005, dalam penentuan nilai tarif tol didasarkan kepada tiga faktor, yaitu kemampuan membayar atau Ability to Pay dan kemauan membayar atau Willingness to Pay pengguna jalan, Besar Keuntungan Biaya Operasi Kendaraan (BKBOK) dan kelayakan investasi. Penelitian ini membahas tentang bagaimana besar nilai tarif tol berdasarkan Ability to Pay (ATP) dan Willingness to Pay (WTP) dari calon pengguna Jalan Tol Jakarta-Cikampek II Selatan. Metode pengumpulan data dilakukan menggunakan teknik survei wawancara kepada 147 responden. Metode analisis data menggunakan metode stastistik deskriptif dengan bantuan perangkat lunak Microsoft Excel dan SPSS V 26. Nilai rata-rata ATP sebesar Rp 1332,42/km. Sedangkan nilai WTP rata-rata yang didapat untuk tarif per kilometer Rp 1111,56/km dan tarif per delta waktu tempuh Rp 888,16/menit. Berdasarkan keterkaitan WTP dengan karakteristik responden didapatkan rentang tarif WTP per kilometer sebesar Rp 1079,55 - Rp 1130,71 dengan nilai rata-rata Rp 1103,77/km dan rentang tarif WTP per delta waktu tempuh $\mathrm{Rp} \mathrm{873,80} \mathrm{-} \mathrm{Rp} \mathrm{897,67} \mathrm{dengan} \mathrm{nilai} \mathrm{rata-rata} \mathrm{Rp} \mathrm{887,59/menit.} \mathrm{Dalam} \mathrm{menentukan} \mathrm{nilai} \mathrm{tarif} \mathrm{tol}$ Japek Selatan digunakan hasil rentang tarif WTP per kilometer. Hasil perhitungan 30\%-35\% BKBOK menunjukan rentang sebesar Rp 1220,198 - Rp 1423,56. Maka, didapatkan jangkauan rentang tarif per kilometer jalan tol Japek Selatan sebesar Rp 1079,55 - Rp 1423,56
\end{abstract}

Kata kunci: ability to pay, BKBOK, japek selatan, tarif, willingness to pay.

\begin{abstract}
The South Jakarta-Cikampek II Toll Road Project is one of the National Strategic Projects which is expected to facilitate the distribution of goods and services, reduce logistics costs, and support the economic potential of industrial estates. According to Government Regulation No. 15 of 2005, the calculation of toll rates is based on three factors, namely the ability to pay and the willingness to pay of road users, the amount of vehicle operating costs (BKBOK) and investment feasibility. This study discusses how the value of the toll tariff is based on the Ability to Pay (ATP) and Willingness to Pay (WTP) of prospective users of the South Jakarta-Cikampek II Toll Road. The method of data collection was carried out using an interview survey technique to 147 respondents. The data analysis method used descriptive statistical methods with the help of Microsoft Excel and SPSS V 26 software. The average value of ATP was Rp 1332,42/km. While the average WTP value obtained for the fare per kilometer is $R p 1111,56 / \mathrm{km}$ and the fare per delta for travel time is $R p 888,16 /$ minute. Based on the relationship between the WTP and the characteristics of the respondents, the WTP tariff range per kilometer is $R p$ 1079,55 - Rp 1130,71 with an average value of $R p 1103,77 / \mathrm{km}$ and the range of WTP rates per delta of travel time is $R p 873,80-R p$ 897,67. with an average value of Rp. 887,59/minute. In determining the rate of the South Japek toll road, the results of the WTP tariff range per kilometer are used. The results of the calculation of 30\%-35\% BKBOK show a range of $R p$ 1220,198 - Rp 1423,56. So, the range of tariffs per kilometer for the South Japek toll road is $R p$ $1079,55-\operatorname{Rp} 1423,56$.
\end{abstract}

Keywords: ability to pay, BKBOK, japek selatan, tarif, willingness to pay.

This is an open access article under the $\underline{C C-N C-S A}$ license. 


\section{PENDAHULUAN}

Jalan tol adalah jalan umum yang merupakan bagian dari sistem jaringan jalan sebagai jalan nasional yang penggunanya diwajibkan membayar tol (Undang-Undang No.38, 2004). Ditinjau dari segi manfaat, jalan tol dapat menguntungkan pengguna berupa adanya penghematan waktu dan Biaya Operasi Kendaraan (BOK) dibandingkan dengan jalan raya umum (Karsaman, et al., 2015). Secara umum penentuan tarif tol harus memastikan biaya yang ditanggung penyedia jasa transportasi serta mempertimbangkan kemampuan dan kemauan membayar pengguna jasa (Allo, 2017). Pada dasarnya penentuan tarif harus menutup seluruh biaya yang ditanggung penyedia jasa transportasi dan sesuai kemampuan membayar pengguna jasa (Nefiadi, 2015). Hal tersebut dimaksudkan agar bisnis jalan tol dapat berjalan sesuai business plan serta dapat menguntungkan bagi pemerintah, badan usaha, dan pengguna jalan tol.

Menurut Peraturan Presiden Nomor 58 tahun 2017 Jalan Tol Jakarta - Cikampek II Selatan (Japek II Selatan) merupakan salah satu bagian dari Percepatan Pelaksanaan Proyek Strategis Nasional. Sebagai proyek yang memiliki sifat strategis untuk peningkatan pertumbuhan dan pemerataan, diharapkan Jalan Tol tersebut dapat mendukung pengembangan potensi ekonomi kawasan industri dan memperlancar distribusi barang serta jasa.

(Hasugian, 2020), dalam penelitiannya yang berjudul Analisis Penetapan Tarif Tol Kualanamu Seksi 7 (Studi Kasus Jalan Tol Sei Rampah - Tebing Tinggi) menjelaskan bahwa Penentuan tarif didasarkan pada 70\% dari Besar Keuntungan Biaya Operasional Kendaraan. Didapatkan hasil untuk golongan I sebesar Rp 9.700 untuk Jalan Tol JMKT Seksi 7. Hasil tersebut semakin memperkuat bahwa perlunya Analisis Tarif Tol berdasarkan Ability to Pay dan Willingness to Pay Rencana Jalan Tol Jakarta - Cikampek II Selatan dengan mempertimbangkan kemampuan dan kemuan membayar masyarakat dan Besar Keuntungan Biaya Operasi Kendaraan dalam penentuan tarif ideal tol Jakarta - Cikampek II Selatan.

Penelitian ini akan membahas mengenai permasalahan bagaimana besaran nilai ATP dan WTP calon pengguna Jalan Tol Japek II Selatan. Kemudian bagaimana keterkaitan karakteristik responden dengan WTP calon pengguna Jalan Tol Japek II Selatan dan bagaimana besaran nilai tarif tol Japek II Selatan berdasarkan tarif tol WTP dengan tarif tol BKBOK.

Tujuan yang dicapai dalam penelitian ini adalah mengetahui besaran nilai ATP dan WTP calon pengguna Japek II Selatan. Kemudian menunjukan hubungan antara karakteristik responden dengan besaran nilai WTP calon pengguna Japek II Selatan dan mengidentifikasi besaran nilai tarif tol Japek II Selatan berdasarkan tarif tol WTP dengan tarif tol BKBOK

Manfaat dari penelitian mengenai analisis terhadap tarif tol Japek II Selatan berdasarkan ATP dan WTP ini diharapkan dapat dijadikan refrensi bagi pihak BUJT PT Jasamarga Japek Selatan dalam penentuan tarif tol Japek II Selatan dan diharapkan mampu menjadi pedoman, atau refrensi gambaran mengenai penentuan tarif jalan tol

\section{METODE}

\section{Objek Penelitian}

Objek penelitian ini adalah Proyek Pembangunan Jalan Tol Jakarta - Cikampek II Selatan.

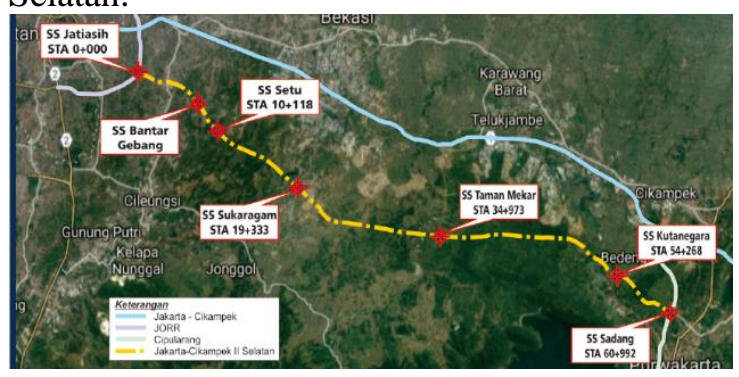

Gambar 1. Objek Penelitian Proyek Jalan Tol

Jakarta - Cikampek II Selatan

Sumber: PT Jasamarga Japek Selatan, Company

Profile Jalan Tol Jakarta - Cikampek II Selatan,

2021

\section{Penentuan Ukuran Sampel}

Pada penyebaran kuesioner penelitian ini menggunakan Rumus Issac Michael. Dengan tingkat kepercayaan $=95 \%$, selanjutnya dengan asumsi tingkat kesalahan (galat) yang diinginkan adalah 5\%, maka, jumlah responden yang dibutuhkan untuk kegiatan survei sebanyak 100 responden. Namun, pada pada penelitian ini jumlah sampel menjadi 147 responden.

\section{Metode Pengumpulan Data}


Pengumpulan data dalam penelitian ini meliputi data primer dan data sekunder

a. Pengumpulan data primer berupa penyebaran kuesioner melalui survei wawancara dengan pendekatan Stated Preference kepada 147 responden. Substansi yang ditanyakan dalam pertanyaan kuesioner yaitu mengenai identitas responden dan karakteristik responden terhadap persepsi kemauan membayar tarif tol. Survei dilakukan di Rest Area KM 57 A JakartaCikampek.

b. Pengumpulan data sekunder terdiri atas data umum proyek, data proyeksi volume LHR, data survei kajian lalu lintas dan data parameter BKBOK yang dilakukan dengan mengajukan permohonan data

\section{Tahapan Penelitian}

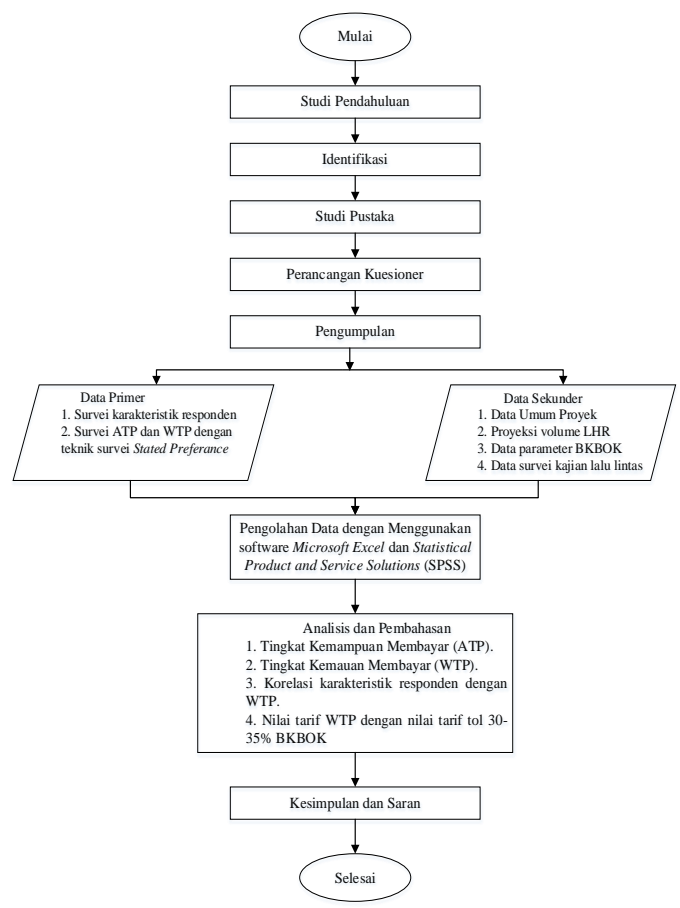

Gambar 2. Bagan Alir Penelitian

\section{HASIL DAN PEMBAHASAN}

\section{Uji Normalitas Data}

Uji normalitas merupakan uji yang dilakukan dengan bertujuan untuk menilai distribusi (sebaran) dari kelompok data atau variabel. Ada dua cara untuk mendeteksi apakah data atau variabel terdistribusi normal atau tidak yaitu dengan analisis grafik dan uji statistik (Ghozali, 2016). Uji kenormalan suatu data dilihat dari nilai per- bandingan skewness dengan Std. Error of Skewness dan nilai perbandingan Kurtosis dengan Std. Error of Kurtosis, harus dianatara -2 dan 2.

Dari hasil pengujian untuk WTP per kilometer didapatkan perbandingan nilai Kurtosis dengan Std. Error of Kurtosis sebesar -1,65 dan untuk WTP per delta waktu tempuh didapatkan perbandingan nilai Kurtosis dengan Std. Error of Kurtosis sebesar 0,297. Berdasarkan analisis didapatkan hasil seluruh data memiliki nilai dengan kriteria pengujian $-2<x<2$. Sehingga disimpulkan bahwa data terdistribusi normal.

\section{Analisis Ability to Pay}

Ability to Pay (ATP) merupakan kemampuan maksimum dari sebagian penghasilan pengguna jalan tol untuk membayar biaya jasa perjalanan di jalan tol (Rumiati, et al., 2013). Perhitungan ATP digunakan sebagai acuan penentuan tarif untuk melihat tolak ukur kemampuan membayar bagi pengguna jalan tol (Armijaya \& Annisa, 2019). Parameter-parameter yang mempengaruhi nilai ATP diantaranya pendapatan per bulan, alokasi biaya transportasi, frekuensi perjalanan (Basuki \& Chuadinata, 2019). Pada penelitian ini nilai ATP dihitung menggunakan travel cost method. Metode ini mengasumsikan sebagian dari penghasilan untuk alokasi biaya transportasi dengan frekuensi perjalanan untuk mengetahui tolak ukur kemampuan membayar per satuan kilometer perjalanan (Ridwan, et al., 2018). Rumus ATP adalah sebagai berikut

$\mathrm{ATP}=\frac{\mathrm{IxxPp} \times \mathrm{Pt}}{\mathrm{Tt}}$

Dimana:

$$
\begin{aligned}
& \text { ATP = Kemampuan membayar } \\
& (\mathrm{Rp} / \mathrm{km}) \\
& \text { Ix }=\text { Pendapatan responden } \\
& \text { perbulan (Rp/bulan) } \\
& \mathrm{Pp} \quad=\text { Persentase biaya transportasi } \\
& \text { per bulan (\%) } \\
& \mathrm{Pt} \quad=\text { Persentase Alokasi untuk } \\
& \text { Biaya Tol per bulan (\%) } \\
& \mathrm{Tt} \quad=\text { Panjang perjalanan perbulan } \\
& \text { pertrip (km/bulan) }
\end{aligned}
$$

Dari 147 responden didapatkan nilai tertinggi sebesar Rp 208333 dan nilai terendah sebesar Rp 33898. Kemudian didapatkan nilai rata-rata kemampuan membayar untuk tol Japek II Selatan sebesar Rp 85275. 


\section{Analisis Wilingness to Pay}

Willingess to Pay (WTP) didefinisikan sebagai nilai maksimum rupiah atas kesedian membayar untuk menghemat satu satuan waktu (Mahalili, 2013). WTP direpresentasikan sebagai nilai waktu penghematan waktu perjalanan atau nilai pertukaran (trade-off) antara waktu perjalanan dan biaya perjalanan.

Besaran nilai WTP dipengaruhi oleh produk yang ditawarkan operator jasa transportasi, kualitas dan kuantitas pelayanan yang diberikan, kenyamanan pengguna dan pendapatan pengguna (Permata, 2012). Nilai WTP masingmasing responden yang didapat merupakan nilai maksimum rupiah yang bersedia dibayarkan. Kemudian data WTP diolah untuk mendapatkan nilai rata-rata dengan rumus sebagai berikut

$M W T P=\frac{1}{n} \sum_{i=1}^{n} W T P i$

Keterangan:

$\begin{array}{ll}\text { MWTP } & \text { Rata-rata WTP } \\ \mathrm{n} & =\text { Jumlah sampel } \\ \text { WTPi } & =\text { Nilai WTP maksimum re- } \\ & \text { ponden ke-i }\end{array}$

\section{Analisis WTP per Kilometer dan WTP} per Delta Waktu Tempuh

Analisis WTP ini untuk memperoleh nilai ratarata WTP per kilometer dan WTP per delta waktu tempuh dengan cara melihat nilai ratarata hitung (mean). Berikut hasil olahan data hasil kuesioner menggunakan SPSS V 26 disajikan sebagai berikut

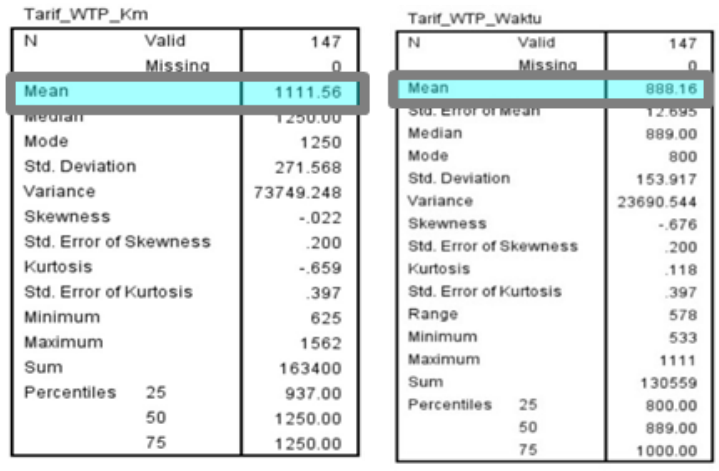

Gambar 3. Hasil Frekuensi Tarif WTP per Km dan per Delta Waktu Tempuh

\section{Analisis Hubungan Willingness to Pay (WTP) dengan antar variabel}

Analisis hubungan antar variabel dengan WTP dilakukan dengan pengujian cross tab menggunakan perangkat lunak SPSS. Keseluruhan nilai rata-rata analisis tersebut mempresentasikan keseluruhan pilihan responden

Berdasarkan hasil uji statistik deskriptif dari setiap variabel karakteristik yang diuji didapatkan rekapitulasi hasil sebagai berikut.

Tabel 1. Hasil Rekapitulasi WTP per Kilometer dengan Karakteristik Responden

\begin{tabular}{ll}
\hline \multicolumn{1}{c}{ Variabel } & \multicolumn{1}{c}{ Nilai WTP } \\
\hline Jenis Kelamin & Rp 1129,01 \\
\hline $\begin{array}{l}\text { Alokasi Biaya Transportasi } \\
\text { per Bulan }\end{array}$ & $\mathrm{Rp} \mathrm{1095,70}$ \\
\hline Pendapatan per Bulan & $\mathrm{Rp} \mathrm{1083,90}$ \\
\hline $\begin{array}{l}\text { Alasan Menggunakan Jalan } \\
\text { Tol }\end{array}$ & $\mathrm{Rp} \mathrm{1130,71}$ \\
\hline $\begin{array}{l}\text { Frekuensi Penggunaan } \\
\text { Jalan Tol }\end{array}$ & $\mathrm{Rp} \mathrm{1079,55}$ \\
\hline Nilai Rata-rata & Rp 1103,77 \\
\hline
\end{tabular}

Berdasarkan hasil rekapitulasi nilai rata-rata tarif WTP per kilometer dibuat rentang tarif Rp $1.079,55-\mathrm{Rp} 1.130,79$ per kilometer. Sehingga didapatkan nilai rata-rata sebesar $\mathrm{Rp}$. $1.103,77 / \mathrm{km}$.

Jika rentang tarif dikalikan dengan panjang trase rencana jalan tol Japek II Selatan sepanjang $64 \mathrm{~km}$ maka rentang tarif menjadi $\mathrm{Rp}$ 69.091 - Rp 72.365.

Tabel 2. Hasil Rekapitulasi WTP per Delta waktu tempuh dengan Karakteristik Responden

\begin{tabular}{ll}
\hline \multicolumn{1}{c}{ Variabel } & \multicolumn{1}{c}{ Nilai WTP } \\
\hline Jenis Kelamin & $\mathrm{Rp} \mathrm{897,67}$ \\
\hline $\begin{array}{l}\text { Alokasi Biaya Transportasi } \\
\text { per Bulan }\end{array}$ & $\mathrm{Rp} \mathrm{888,07}$ \\
\hline Pendapatan per Bulan & $\mathrm{Rp} \mathrm{890,49}$ \\
\hline $\begin{array}{l}\text { Alasan Menggunakan Jalan } \\
\text { Tol }\end{array}$ & $\mathrm{Rp} \mathrm{887,90}$ \\
\hline $\begin{array}{l}\text { Frekuensi Penggunaan Jalan } \\
\text { Tol }\end{array}$ & $\mathrm{Rp} \mathrm{873,80}$ \\
\hline Nilai Rata-rata & $\mathbf{R p ~ 8 8 7 , 5 9}$ \\
\hline
\end{tabular}

Hasil analisis disajikan dalam grafik Pada Gambar 4 .

Berdasarkan hasil rekapitulasi nilai rata-rata tarif WTP per delta waktu tempuh dibuat rentang tarif Rp 873,80 - Rp 897,67 per menit. Sehingga didapatkan nilai rata-rata sebesar Rp. $887,59 /$ menit delta waktu. 


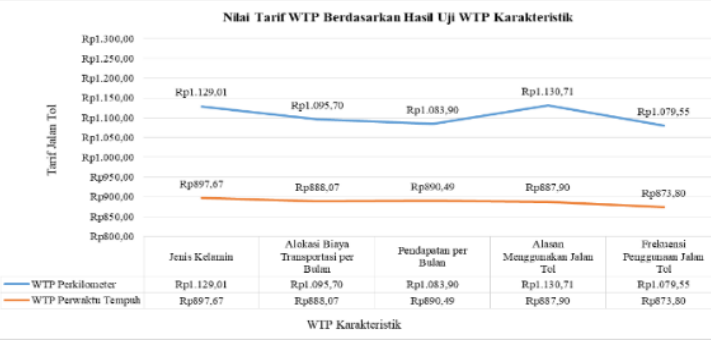

Gambar 4. Grafik Hubungan Nilai WTP dengan Variabel Karakteristik Responden

Kemudian didapatkan hasil apabila melewati jalan tol Japek II Selatan pengguna jalan tol menghabiskan waktu tempuh selama 75 menit dengan asumsi kecepatan rata-rata $80 \mathrm{~km} / \mathrm{jam}$. Kemudian hasil hubungan antara tarif tol per delta waktu tempuh melewati jalan tol Japek II Selatan dengan asumsi waktu tempuh 75 menit didapatkan rentang tarif sebesar Rp 65535 - Rp 67325 .

\section{Analisis Tarif Tol berdasarkan BKBOK}

\section{Biaya Operasi Kendaraan}

Biaya Operasi Kendaraan (BOK) terdiri dari dua komponen yaitu biaya tetap (standing cost) dan biaya tidak tetap (running cost). Pada penelitian ini perhitungan BOK menggunakan model Pacific Consultant International (PCI).

Adapun parameter BOK yang diperhitungkan dalam model PCI terdiri dari biaya konsumsi bensin, konsumsi oli, pemakaian ban, pemeliharaan, waktu perjalanan, depresiasi, suku bunga, asuransi (PCI, 2000).

Biaya Operasi Kendaraan yang dianalisis pada penelitian ini adalah BOK golongan I dengan harga satuan yang digunakan didasarkan pada harga pasar tahun 2020 - 2021. Parameter BOK yang dihitung merupakan biaya konsumsi bensin, konsumsi oli, pemakaian ban, pemeliharaan, waktu perjalanan, depresiasi, suku bunga, asuransi. Didapatkan hasil dari perhitungan BOK jalan tol dengan asumsi kecepatan $80 \mathrm{~km} / \mathrm{jam}$ sebesar 2357,58 Rp/km dan BOK jalan arteri dengan asumsi kecepatan $25 \mathrm{~km} / \mathrm{jam}$ sebesar 4888,97 Rp/km. Hasil tersebut selanjutnya akan digunakan untuk analisis BKBOK.

\section{Nilai Waktu}

Nilai Waktu Perjalanan (Time Value) atau penghematan waktu didefinisikan sebagai penghematan waktu perjalanan yang timbul akibat adanya peningkatan karena kemacetan dikurangi, batas kecepatan dinaikkan atau tersedia rute yang lebih nyaman (Wathan, et al., 2019).

Perhitungan ini didasarkan pada teori Herbert Mohring yang mengasumsikan bahwa pengendara cenderung mencari rute dengan biaya operasi kendaraan yang minimal dan beberapa alternatif yang tersedia. Rumus nilai waktu sebagai berikut.

$P=S[c-F(S)]$

Keterangan:

$\mathrm{P}=$ Nilai waktu sesuai dengan jenis kendaraan (Rp/jam)

$\mathrm{F}=$ Biaya Operasi Kendaraan $(\mathrm{Rp} / \mathrm{km})$

$\mathrm{c}=$ Total Jumlah Biaya Operasi Kendaraan (Rp/jam)

$\mathrm{S}=$ Kecepatan dalam perjalanan $(\mathrm{km} / \mathrm{jam})$

Berdasarkan rumus tersebut didapatkan hasil untuk nilai waktu golongan 1 sebesar 66580 (Rp/jam). Hasil tersebut selanjutnya akan digunakan untuk analisis BKBOK

\section{BKBOK}

Besar Keuntungan Biaya Operasi Kendaraan (BKBOK) diatur dalam PP No. 15 tahun 2005 tentang Jalan Tol. Peraturan ini menjelaskan bahwa BKBOK dihitung berdasarkan selisih biaya operasi kendaraan dan nilai waktu pada jalan tol dengan jalan arteri atau jalan umum yang ada.

Analisis ini membahas mengenai nilai tarif WTP dengan jangkauan nilai tarif tol BKBOK yang dihitung. Besaran tarif tol harus $\leq 70 \%$ BKBOK (Wathan, et al., 2019). Dalam penelitian ini akan digunakan nilai $30 \%-35 \%$ dari BKBOK.

Adapun formula penghitungan BKBOK sebagai berikut.

$B K B O K=[(B O K a \times D a)-($ BOKt $\times D t)]+$ $\left[\left(\frac{D a}{V a}-\frac{D t}{V t}\right)\right] \times T v$

Keterangan:

$\begin{array}{ll}\text { BKBOK }= & \text { Besar Keuntungan Biaya } \\ & \text { Operasi Kendaraan }(\mathrm{Rp}) \\ \text { BOKa } & =\text { BOK di Jalan arteri }(\mathrm{Rp} / \mathrm{jam}) \\ \mathrm{BOKt} & =\text { BOK di Jalan Tol }(\mathrm{Rp} / \mathrm{jam}) \\ \mathrm{Da} & =\text { Jarak Jalan Arteri }(\mathrm{km})\end{array}$




$\begin{array}{llll}\mathrm{Dt} & = & \text { Jarak Jalan Tol }(\mathrm{km}) \\ \mathrm{Va} & =\begin{array}{l}\text { Kecepatan di Jalan } \\ (\mathrm{km} / \text { jam})\end{array} \\ \mathrm{Vt} & =\begin{array}{l}\text { Kecepatan di Jalan } \\ \text { (km/jam) }\end{array} \\ & \text { Nilai Waktu } & \text { Tol } \\ \mathrm{Tv} & \end{array}$

Berdasakan hasil perhitungan BKBOK untuk golongan 1 didapatkan nilai sebesar Rp 260309. Pada penelitian ini diambil rentang nilai BKBOK jalan tol sebesar $30 \%-35 \%$ dari BKBOK.

Dengan jarak jalan tol Japek II Selatan sepanjang $64 \mathrm{~km}$ maka didapatkan nilai besaran tarif tol berdasarkan BKBOK per kilometer untuk $30 \%$ sebesar Rp 1220,198 dan untuk 35\% sebesar Rp 1423,56.

Pada penelitian ini didapatkan nilai tarif jalan tol dengan jangakuan rentang tarif per kilometer sebesar Rp 1079,55 - Rp 1424,56 atau jika dikalikan panjang trase jalan tol Japek II Selatan $64 \mathrm{~km}$ maka didapatkan rentang nilai tarif sebesar Rp 69901 - Rp 91108.

Berdasarkan hasil nilai ATP pada analisis sebelumnya didapat nilai sebesar Rp 85275 sehingga nilai tersebut memenuhi rentang nilai kemauan membayar yang didapatkan sebesar Rp 69901 - Rp 91108.

\section{SIMPULAN}

Berdasarkan hasil analisis Ability to Pay dan Willingness to Pay dari 147 responden yang sudah dilakukan survei wawancara pada Rest Area KM 57, maka dapat diperoleh kesimpulan hasil rata-rata nilai Ability to Pay atau Kemauan Membayar responden sebesar Rp 1333,42/km dan nilai rata-rata Willlingness to Pay atau Kemauan Membayar responden untuk Tarif WTP per kilometer sebesar Rp 1111,56/km kemudian nilai rata-rata Willingness to Pay atau Kemauan Membayar responden untuk tarif WTP per delta waktu tempuh sebesar Rp $888,16 /$ menit. Kemudian hasil uji statistik deskriptif dari setiap variabel karakteristik responden, dengan variabel karakteristik yang diuji berupa jenis kelamin, alokasi biaya transportasi per bulan, pendapatan per bulan, alasan menggunakan jalan tol, frekuensi menggunakan jalan tol didapatkan rentang tarif WTP per kilometer sebesar Rp 1079,55/km - Rp 1130,77/km dan rentang tarif WTP per delta waktu tempuh sebesar Rp 873,80/menit - Rp 897,67/menit.
Selanjutnya, berdasarkan perhitungan Wilingness to Pay per kilometer dengan tarif tol BKBOK didapatkan besaran nilai tarif tol Jakarta - Cikampek II Selatan berada pada jangkauan rentang tarif sebesar 1079,55/km Rp 1423,56/km atau Rp 69091 - Rp 91108.

Berdasarkan nilai Ability to Pay dan Willingness to Pay, penelitian ini dapat dikembangkan dengan mempertimbangkan analisis finansial proyek Jalan Tol Jakarta - Cikampek II Selatan agar bisnis jalan tol dapat berjalan sesuai business plan serta dapat menguntungkan bagi pemerintah, badan usaha, dan pengguna jalan tol serta dapat melanjutkan dengan asumsi bahwa akan ada potensi tarif terintegrasi pada jaringan di wilayah Jakarta - Cikampek.

\section{UCAPAN TERIMAKASIH}

Ucapan terima kasih penulis sampaikan kepada UP2M Politeknik Negeri Jakarta yang telah mendanai penelitian ini dalam program BTAM 2021.

\section{DAFTAR PUSTAKA}

Allo, R. B. T. T., 2017. Studi Kelayakan Ekonomi dan Finansial Rencana Pelebaran Jalan Tol WaruSidoarjo. Jurnal Rekayasa Teknik Sipil, Vol 01, pp. 39-48.

Armijaya, H. \& Annisa, A., 2019. Kajian ATP dan WTP Tol Kanci - Semarang. Jurnal Perencanaan Wilayah dan Kota Institut Teknologi Sains Bandung, Vol 2, p. 2.

Basuki, I. \& Chuadinata, S., 2019. Analisis Ability to Pay dan Willingness to Pay Jasa Kereta Api Yogyakarta International Airport. pp. 140-146.

Ghozali, I., 2016. Aplikasi Analisis Multivariete dengan Program IBM SPSS 23.. i: Semarang: Badan Penerbit Universitas Diponegoro.

Hasugian, G. Y., 2020. Analisa Penetapan Tarif Harga Jalan Bebas Hambatan pada Proyek Pembangunan Jalan Tol Bebas Hambatan Jasa Marga Kualanamu Tol Seksi 7 : Sei Rampah Tebing Tinggi. p. 14.

Karsaman, R. H., Rodhiatun, Rasyid, H. A. \& Santoso, I., 2015. Kajian Investasi Pembangunan Jalan Tol di Indonesia Berdasarkan Sistem Syariah: Studi Kasus Jalan Tol Cikampek -Palimanan. Jurnal Perencanan Wilayah dan Kota, pp. 86-99.

Mahalili, K., 2013. Analisis Ability to Pay dan Willingness to Pay Pengguna Jasa Kereta Api Kuala 
Namu (Airport Railink Service). Jurnal Ekonomi dan Keuangan, Vol 2, p. 3.

Nefiadi, E. N., 2015. Problema dan Formulasi Tarif Sektor Transportasi.

PCI, 2000. PT Pasific Consultant International (PCI) [https://dokumen.tips/documents/perhitungan-bokdengan-rumus-pci-model.html]

Permata, M. A., 2012. Analisis Ability to Pay dan Willingness to Pay Jasa Kereta Api Bandara Soekarno Hatta - Manggarai.

Ridwan, U., Priyatno, S. \& Suparna, L., 2018. Analisis ATP dan WTP Pengguna Sepeda Motor, Mobil Pribadi, dan Bus di Wilayah Yogyakarta dan
Bantul terhadap Pengoperasian Kereta Api Perkotaan. Jurnal Riset Daerah, Vol 17, p. 1.

Rumiati, R., Fahmi, K. \& Edison, B., 2013. Analisis Kemampuan dan Kemauan Membayar Tarif Angkutan Umum Mini Bus di Kabupaten Rokan Hulu. Jurnal Mahasiswa Teknik UPP, Vol 1.

Undang-Undang No.38, t. J., 2004. Undang-Undang No. 38. i: UU No. 38 Tahun 2004 tentang Jalan. Jakarta: Sekretariat Negara, p. Lembaran RI Tahun 2004 No. 132.

Wathan, H. Q., Isya, M. \& Sugiarto, S., 2019. Studi Penentuan Tarif Tol Rencana Ruas Jalan Tol Banda Aceh - Sigli. Teras Jurnal, Vol 9, p. 2. 